See Article page 1156.

\section{Commentary: The rose continues to smell sweetly}

\author{
Robert H. Anderson, BSc, MD, PhD (Hon), FRCPath, \\ FRCS Ed (Hon)
}

It is now almost 40 years that Anton Becker and I posed the question, when considering the morphology of the lesion now almost uniformly described as an atrioventricular septal defect, whether a rose by any other name would smell as sweet? ${ }^{1}$ As the group from Seattle Children's Hospital acknowledge, the phenotypic feature of the hearts in question is the commonality of the atrioventricular junction. ${ }^{2}$ They correctly point to the fact that this feature can properly be interpreted as retention of the embryonic atrioventricular canal. The key feature that has changed in overall interpretation of the morphology, however, has been recognition that the so-called cleft is the zone of apposition between the left ventricular components of the leaflets of the common valve that bridge the ventricular septum. Because of the commonality of the atrioventricular junction, this left atrioventricular valve is a trifoliate structure. It cannot be compared with the bifoliate morphologically mitral valve. This was part of the features emphasized by Becker and myself in our review published in the Journal nearly 4 decades ago. ${ }^{1}$ Indeed, it was the trifoliate nature of the left atrioventricular valve that alerted the authors to the fact that the unifying phenotypic feature of the patients they describe was the commonality of the atrioventricular junction. They might have stated that confusion has also long surrounded the "ventricular septal defect of atrioventricular canal type." For quite some time, the defect found in the setting of straddling and overriding of the tricuspid valve was described in this fashion. ${ }^{3}$ It is now accepted that this

\footnotetext{
From the Biosciences Institute, Newcastle University, Newcastle upon Tyne, United Kingdom.

Disclosures: The author reported no conflicts of interest.

The Journal policy requires editors and reviewers to disclose conflicts of interest and to decline handling or reviewing manuscripts for which they may have a conflict of interest. The editors and reviewers of this article have no conflicts of interest.

Received for publication June 16, 2021; revisions received June 16, 2021; accepted for publication June 16, 2021; available ahead of print June 24, 2021.

Address for reprints: Robert H. Anderson, BSc, MD, PhD (Hon), FRCPath, FRCS Ed (Hon), 60 Earlsfield Rd, London SW18 3DN, United Kingdom (E-mail: sejjran@ ucl.ac.uk).

J Thorac Cardiovasc Surg 2022;163:1163-4

$0022-5223 / \$ 36.00$

Copyright (C) 2021 by The American Association for Thoracic Surgery

https://doi.org/10.1016/j.jtcvs.2021.06.030
}

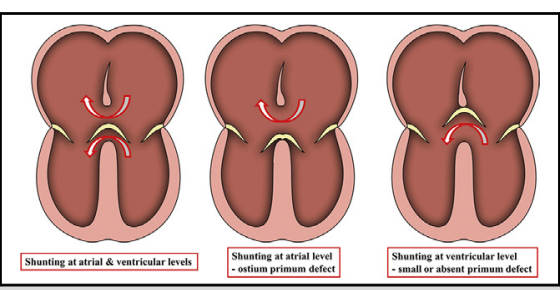

The diagram shows the potentials for shunting through an atrioventricular septal defect.

\section{CENTRAL MESSAGE \\ Shunting through an atrioven- tricular septal defect with a common atrioventricular junc- tion reflects the relationship of the bridging leaflets to the atrial and ventricular septal structures.}

lesion is properly described as a perimembranous defect with atrioventricular septal malalignment. ${ }^{4}$ The recognition of the ventricular septal malalignment is the more important, because when the ventricular septum does not reach to the crux, the conduction axis arises from an anomalous atrioventricular node. ${ }^{5}$ One of the patients undergoing surgery in Seattle experienced atrioventricular dissociation. The authors correctly presume, nonetheless, that in the setting of common atrioventricular junction, the conduction axis will arise from a node inferiorly displaced to be positioned at the crux of the heart. ${ }^{6}$ The key feature of their patients is the adjacency of the bridging leaflets to the leading edge of the primary atrial septum. It is the overall relationship of the bridging leaflets to the septal components that determines the anatomic potential for shunting across the atrioventricular septal defect (Central Image). In this setting, shunting will be through the atrial or ventricular components of the atrioventricular septal defect. It is a mistake to describe these spaces as "atrial" or "ventricular" septal defects. It is the precision of nomenclature as achieved by the group from Seattle that will now enhance the understanding of this rare variant of atrioventricular septal defect with a common atrioventricular junction.

\section{References}

1. Becker AE, Anderson RH. Atrioventricular septal defects. What's in a name? J Thorac Cardiovasc Surg. 1982;83:461-9.

2. Kwon MH, Schultz AM, Le M, Permut LC, McMullan M, Nuri MK. Complete atrioventricular septal defect with absent or diminutive primum component: 
incidence, anatomic characteristics, and outcomes. J Thorac Cardiovasc Surg. 2022; 163:1156-62.

3. LaCorte MA, Cooper MS, Kauffman SL, Schiller MS, Golinko RJ, Griepp RG. Atrioventricular canal ventricular septal defect with cleft mitral valve. Angiographic and echocardiographic features. Pediatr Cardiol. 1982;2:289-95.

4. Lopez L, Houyel L, Colan SD, Anderson RH, Beland MJ, Aiello VD, et al. Classification of ventricular septal defects for the eleventh iteration of the international classification of diseases_-striving for consensus: a report from the International
Society for Nomenclature of Paediatric and Congenital Heart Disease. Ann Thorac Surg. 2018;106:1578-89.

5. Spicer DE, Anderson RH, Backer CL. Clarifying the surgical morphology of inlet 446 ventricular septal defects. Ann Thorac Surg. 2013;95:236-41.

6. Yoshitake S, Kaneko Y, Morita K, Hoshino M, Nagashima M, Takahashi M, et al Reassessment of the location of the conduction system in atrioventricular septal defect using phase-contrast computed tomography. Semin Thorac Cardiovasc Surg. 2020;32:860-8.
See Article page 1156.

\section{Commentary: Beware the AVSD with no "A"}

\section{Carl L. Backer, MD}

Kwon and colleagues ${ }^{1}$ from Seattle Children's have provided an interesting review of a unique subgroup of patients with atrioventricular septal defect (AVSD). These are the patients with AVSD and no "A"; that is, AVSD with an absent or very small atrial component but still a common atrioventricular junction with a common $\mathrm{AV}$ valve. In their series of 249 patients with AVSD, only $16(6 \%)$ had either no atrial component or a diminutive atrial component. This unique group of patients demonstrates how truly varied morphologic phenotypes can exist within the genotype of AVSD.

The authors describe important surgical caveats for surgeons to consider when encountering patients with this variant of AVSD. The first is that when presented with a patient with an inlet muscular VSD and mitral valve insufficiency, a surgeon should be suspicious and be prepared to deal with this particularly unique anatomy. Closing a simple inlet VSD with a patch is a much different operation than repairing a complete AVSD with no atrial component.

\footnotetext{
From the Section of Pediatric Cardiothoracic Surgery, UK HealthCare Kentucky Children's Hospital, Lexington, Ky; and Cardiothoracic Surgery Department, Heart Institute, Cincinnati Children's Hospital Medical Center, Cincinnati, Ohio. Disclosures: The author reported no conflicts of interest.

The Journal policy requires editors and reviewers to disclose conflicts of interest and to decline handling or reviewing manuscripts for which they may have a conflict of interest. The editors and reviewers of this article have no conflicts of interest.

Received for publication June 24, 2021; revisions received June 24, 2021; accepted for publication June 25, 2021; available ahead of print July 1, 2021.

Address for reprints: Carl L. Backer, MD, Section of Pediatric Cardiothoracic Surgery, UK HealthCare Kentucky Children's Hospital, 800 Rose St, C-259, Lexington, KY 40536-0293 (E-mail: Carl.Backer@uky.edu).

J Thorac Cardiovasc Surg 2022;163:1164-5

$0022-5223 / \$ 36.00$

Copyright (c) 2021 by The American Association for Thoracic Surgery

https://doi.org/10.1016/j.jtcvs.2021.06.057
}

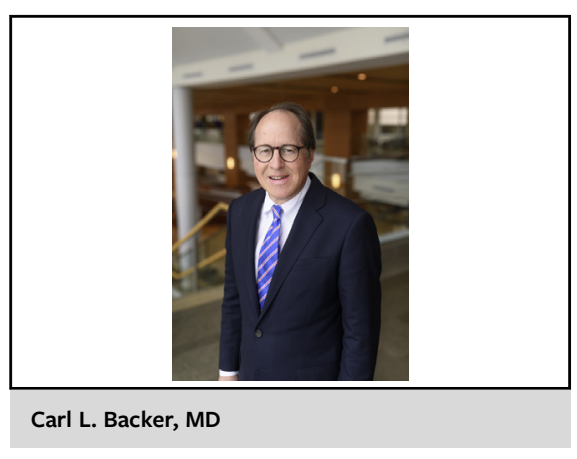

CENTRAL MESSAGE

Children with AVSD can present with a common AV junction, but no atrial component. These patients will have a technically challenging left AV valve repair and other anatomic nuances that

The next surgical lesson is that adequate exposure to assess the anatomy and effect a durable repair nearly always requires opening the atrial septum. As the authors note, it is quite safe to incise the atrial septum through the fossa ovalis inferiorly and then at $90^{\circ}$ from the midpoint of this incision toward the common AV valve without causing AV block. This is by far the best way to assess the left AV valve and close the cleft or as some prefer to call it, the zone of apposition.

Another surgical issue pointed out by the authors and something I have noted in patients I have operated on is that it is not uncommon in this group to have chordae crossing from the left ventricle to support the right AV valve. Being prepared to encounter these crossing cords enables a surgeon to be ready to cut secondary cords not needed for AV valve competence that interfere with closure of the VSD. 